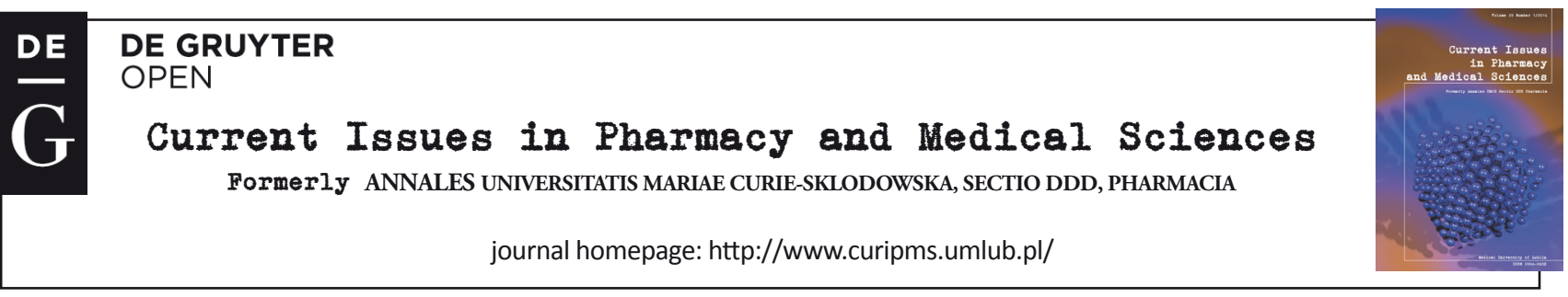

\title{
Pericardial tamponade as the first manifestation of bronchial adenocarcinoma
}

\author{
Kuzemko Dorota ${ }^{1}$, Baranowski Dariusz ${ }^{1}$, Prystupa Andrzej ${ }^{1}$, \\ Fidor-Mikita Ewa ${ }^{2}$, Lachowska-Kotowska Patrycja ${ }^{1}$, Dzida Grzegorz ${ }^{1}$ \\ ${ }^{1}$ Chair and Department of Internal Diseases Medical University of Lublin Independent Clinical Hospital No. 1 in Lublin, Staszica 16, \\ 20-081 Lublin, Poland. \\ 2 Second Department of Radiology Medical University of Lublin
}

\begin{tabular}{|c|c|}
\hline ARTICLE INFO & ABSTRACT \\
\hline $\begin{array}{l}\text { Received } 22 \text { June } 2016 \\
\text { Accepted } 25 \text { August } 2016\end{array}$ & $\begin{array}{l}\text { Case report. A 58-year-old woman was admitted to the Department of Internal Diseases } \\
\text { due to resting dyspnoea, tachycardia and malaise. Her chest X-ray revealed inflammatory }\end{array}$ \\
\hline $\begin{array}{l}\text { Keywords: } \\
\text { cardiac tamponade, } \\
\text { lung neoplasms, } \\
\text { pericar. }\end{array}$ & $\begin{array}{l}\text { lesions, and empiric antibiotic therapy was initiated. Chest CT was then performed which } \\
\text { showed lung tumours. During hospitalization, the patient suddenly developed cardiogenic } \\
\text { shock induced by pericardial tamponade. The fluid from pericardium was subsequently } \\
\text { collected. An histopathological examination of the fluid showed the presence of atypical } \\
\text { cells. The patient then underwent bronchoscopy, the biopsy material of which revealed } \\
\text { bronchial adenocarcinoma. }\end{array}$ \\
\hline
\end{tabular}

\section{INTRODUCTION}

A 58-year old patient was admitted to the Department of Internal Diseases due to resting dyspnea, tachycardia and malaise. Seventeen days prior to hospitalization, the patient was treated in the Department of Neurology because of multi-focal ischaemic stroke with secondary haemorrhaging of the focus in the right occipital region. Additionally, the patient was diagnosed with deep vein thrombosis of the left extremity, as well as subclinical hyperthyroidism. The patient smoked cigarettes for 40 years; the family history revealed that her father died of lung cancer.

In 2012, the patient underwent mammography, this demonstrating the presence of cysts. A subsequent thin-needle biopsy revealed protein masses mixed with blood, numerous macrophages, mono- and multi-nuclear hemosiderinophages - scattered and in clusters, single groups of apocrine cells with features of degeneration. The repeated mammography showed no relevant lesions.

On admission, the patient's general condition was relatively good; physical examination showed rhythmical heart rate of 120 beats/minute, arterial pressure $-120 / 80 \mathrm{~mm} \mathrm{Hg}$; single crepitant rales were heard over the lung fields. The abdomen was soft, painless on palpation. The patient had no fever.

\footnotetext{
* Corresponding author

e-mail: dorota.kuzemko@gmail.com

phone/fax: +48 815327717
}

Laboratory results revealed substantially elevated levels of D-dimers (15774 ngFEU/ml) and troponins (0.104 ng/ml, $0.117 \mathrm{ng} / \mathrm{ml})$; complete blood count and the remaining laboratory tests were within reference ranges. Her tab. 1 ECG showed no features of new ischaemia; CT angiography of the pulmonary arteries did not demonstrate pulmonary embolism yet showed the enlarged lymph nodes of the mediastinum, $<2 \mathrm{~cm}$ in diameter. A chest X-ray showed a thickened bronchial and peri-bronchial outline, with few micro-mottled and streaky parenchymal inflammatory consolidations. Moreover, via chest CT, lung tumours were found. (Illustations 1a, 1b,2a,2b,3)

In the morning hours, the patient suddenly developed symptoms of cardiogenic shock - manifested as a decrease in arterial pressure to undetectable values. Echocardiography revealed a substantial amount of fluid in the pericardial cavity. US-guided pericardiocentesis was performed and $500 \mathrm{ml}$ of bloody fluid was evacuated. Fluids were intravenously substituted and noradrenaline administered, which resulted in haemodynamic stability. The culture of the fluid did not show increased growth of pathogens or presence of neoplastic cells.

Echocardiography repeated on subsequent days demonstrated the presence of about $2 \mathrm{~cm}$ of fluid in the pericardial sac without the tendency to increase its volume. Repeated US of the pleural cavity revealed fluid accumulation in the left pleural cavity. US-guided thoracocentesis was performed 

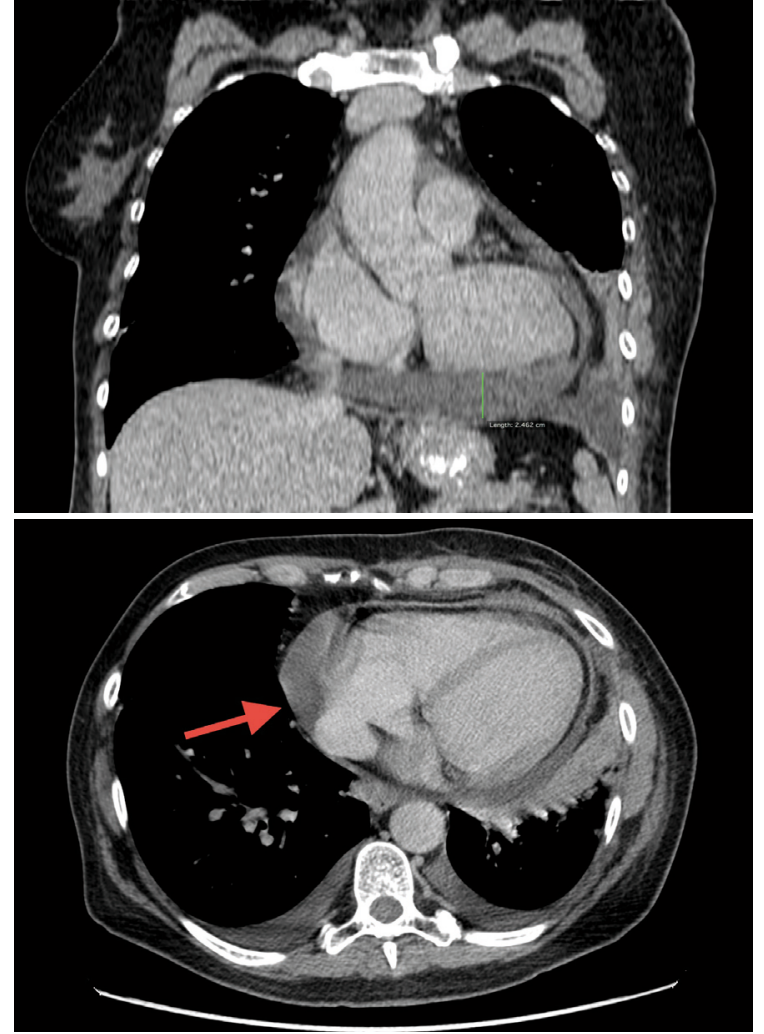

Illustration 1. Chest CT image showing the fluid in the pericardium 1a marked for measuring the amount of accumulated liquid $1 b$ fluid level indicated by the arrow

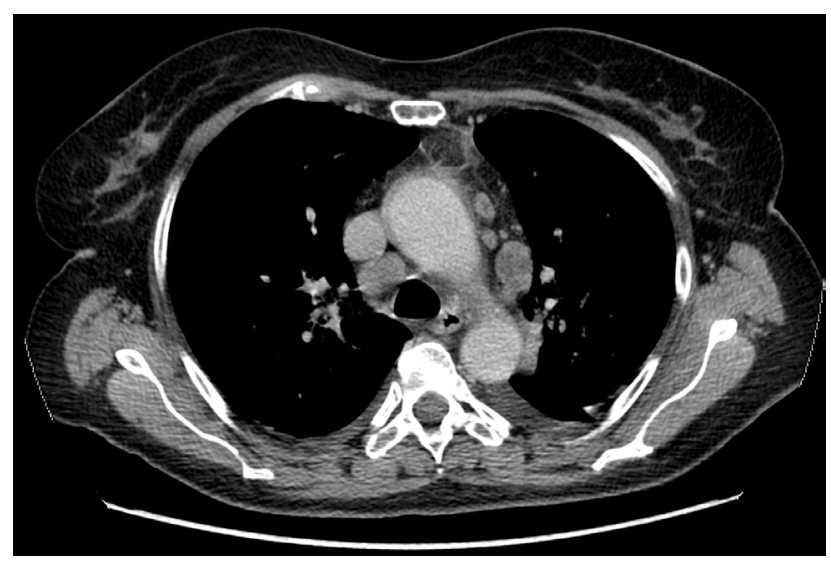

Illustration 3. Chest CT image showing the mediastinal lymphadenopathy

and $600 \mathrm{ml}$ of bloody fluid evacuated. Due to repeated episodes of fluid accumulation, the fluid was additionally evacuated three times, $600 \mathrm{ml}, 500 \mathrm{ml}$ and $900 \mathrm{ml}$ of bloody fluid were removed, respectively. No features of increased growth of pathogens were detected in the collected samples; tuberculosis was excluded. Pathomorphological examination of the fluid showed numerous cells of the activated intermembrane with features of atypia. In some of these, abnormal mitotic figures, histiocytes and lymphocytes were visualized. The image was suggestive of a neoplastic process. The patient also underwent spirometry. This demonstrated moderate obturation with static values within the normal ranges and substantially increased airway resistance.

During hospitalization, thrombocytopaenia was observed, and 2 bags of platelet concentrate were transfused, which
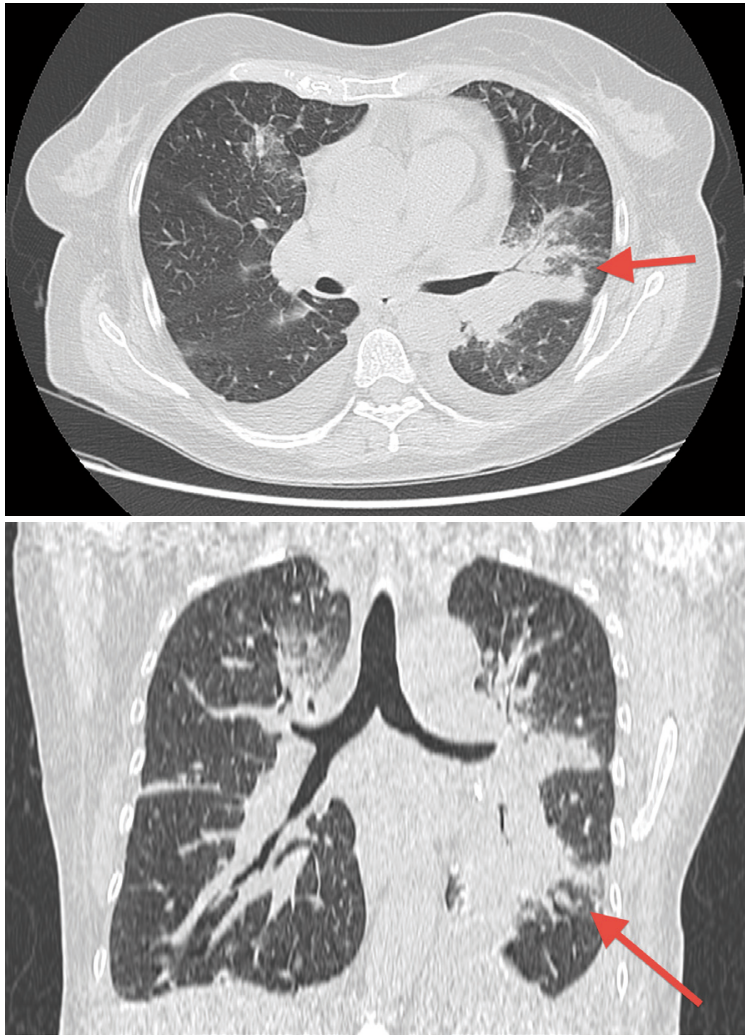

Illustration 2a,b. Chest CT image showing the lung tumour (segmental bronchus extended with component stalactite around)

improved the morphological picture of blood. Based on laboratory results, as well as pathomorphological and imaging results, bronchial carcinoma was suspected. The patient was transferred to the Department of Pulmonology for bronchoscopy followed by videothoracoscopy carried out in the Department of Thoracic Surgery to confirm the diagnosis.

Bronchoscopy revealed macroscopic infiltrative lesions in the left bronchus. Biopsy samples were then taken for histopathological examination. These demonstrated adenocarcinoma of the bronchus. During hospitalization in the Department of Pulmonology, the patient's condition deteriorated and she died due to cardiac arrest.

\section{DISCUSSION}

The heart is the most common place of metastases. These constitute $5-10 \%$ of all causes of death due to carcinoma, and the incidence of diseases with metastases is 16 times higher than that of primary carcinoma $[1,2,3]$. The most common neoplasms inducing pericardial exudates are metastatic tumours, particularly of lung, breast and stomach, as well as colon cancers or tumours of the haematopoietic and lymphatic systems. The pericardium is most frequently affected during the diffuse stage of neoplastic disease. The presence of a pericardial exudate as an essential manifestation of malignant neoplasm is rare $[4,5]$.

The above described process can result from continuity infiltration (e.g. mesothelioma, lung cancer) or be induced via the blood-derived (predominantly breast cancer, melanoma) and/or lymphatic routes. The most likely pathogenesis of pericardial metastases was put forward by Fraser et al., 
who analysed the routes of metastasis in patients with cancers of various origins, from the primary focus, to the pericardium. Their observations disclose neoplastic cells infiltration to mediastinal lymph nodes in the initial stage, and retrograde spread of metastasis to the cardiac lymphatic system through the epicardial plexus. This then leads to obstruction of lymphatic drainage and pericardial fluid accumulation. The fluid accumulating in the pericardial sac results in haemodynamic disorders and cardiogenic shock $[6,7]$.

Clinical symptoms emerge due to pericardial, muscular tissue and endocardial infiltration of neoplastic cells. These include constrictive pericarditis, myocardial infiltration with stagnant failure, arrhythmias and fluid accumulation in the prechordal sac with possible tamponade. The pericardial exudate is the most common manifestation of cardiac involvement by neoplastic cells $[2,8,9]$. Noteworthy, pericardial metastases are usually clinically asymptomatic. Only $29 \%$ of all patients with metastases develop cardiac symptoms, and only $9 \%$ are diagnosed before death.

Pericardial tamponade is observed in $16 \%$ of all patients. In the majority of cases, it develops in neoplastic diseases $(61 \%)$, such as lung and bronchial cancer or neoplastic metastases to the pericardium. In $40 \%$ of all cases, cardiac tamponade is caused by metastatic lung cancer, histopathologically most commonly adenocarcinomas. The development of tamponade evidences the advanced stage of disease, and is a prognostically adverse factor. However, it only remotely occurs as the first manifestation of neoplastic disease [10].

Cardiac tamponade is an acute life-threatening condition. The fluid accumulating in the pericardial sac leads to haemodynamic disorders and development of cardiogenic shock. Moreover, incremental fluid volumes result in positive intrapericardial pressure, which leads to compression of the cardiac wall and impaired filling of its cavities. Despite unchanged efficiency of the myocardium, symptoms of circulatory failure develop due to decreased preload [11]. The clinical picture predominantly shows the symptoms of "low stroke volume". On physical examination, patients most commonly report dyspnoea increasing in the recumbent position and chest pain in the chest. Moreover, deteriorated exercise tolerance, dysphagia and cough are observed. In some cases, fainting and loss of consciousness are also found. A substantial exudate or rapid pericardial fluid increments can be accompanied by the symptoms of Beck triad, i.e. hypotension ( systolic pressure $<90 \mathrm{mmHg}$ ), poorly detectable pulse, jugular venous distension, muffled heart sounds. Paradoxic pulse is observed (reduced amplitudes of inspiratory arterial pressure $\geq 20 \mathrm{mmHg}$ ) [12]. However, lack of these symptoms does not exclude possible development of cardiac tamponade. During the classic process, heart sounds are weak and remote; in malignant neoplastic diseases, heart sounds can remain loud, which is associated with secondary increase in sound transmission by the tumour. In slowly increasing tamponade, symptoms similar to those in right ventricular heart failure predominate [13]. Pericardial tamponade should be suspected in all cases of circulatory arrest with electromechanical dissociation and jugular vein distension [14].
The diagnosis is based on clinical examination; the most relevant, yet also most simple and sensitive method is twodimensional echocardiography (2D echo) with Doppler ultrasound. Echocardiographic monitoring is also important to control an increasing exudate and to diagnose early pericardial constriction [15].

A large amount of fluid in the pericardial sac is one of the earliest signs of tamponade of a swinging heart, and the presence of $20 \mathrm{~mm}$ of pericardial fluid is considered a large exudate. Fluid in the pericardial sac results in increased pericardial pressure exceeding the pressure in the heart cavities. This leads to transient collapsing of their walls. Initially, compression of the heart cavities with physiologically lower pressures (the right atrium (RA), right ventricle (RV) and subsequently of the cavities with higher pressures (the left atrium (LA), left ventricle (LV)) is observed. The free RV wall collapses first; during the final diastole, the RA wall collapses. RA collapse occurs very frequently and is a relatively sensitive indicator [16]. Still, the most specific echocardiographic sign of pericardial tamponade is high respiratory variation in mitral inflow $(>25 \%)$. Respiratory variation in tricuspid, mitral and aortic flows is a echocardiographic manifestation of pulsus paradoxus [17].

ECG recording can remain normal, although sinus tachycardia, reduced amplitudes of QRS complexes and T waves are quite commonly observed. In advanced stages, patients develop bradycardia. Low wave voltage is also found via ECG tracings [18].

Chest X-ray commonly visualises an enlarged heart silhouette resembling a bottle (the 'water bottle' sign). However, radiograms can show normal heart silhouettes. It should be remembered that due to its low specificity, X-ray could only be an auxiliary examination [13].

Cardiac tamponade is a rapidly developing state; its prognosis depends on quick diagnosis and treatment. It always requires hospital therapy. In symptomatic patients, emergency pericardiocentesis is necessary.

Injection into the pericardial sac and evacuation of fluid is indicated when the echocardiographic thickness of the fluid layer exceeds $20 \mathrm{~mm}$. Drainage of up to 1 litre of fluid is recommended to prevent acute right ventricular distension, and the pericardial sac drainage is maintained until the fluid volume decreases below $25 \mathrm{ml} /$ day [19]. The sac injection is also of diagnostic importance, as in the pericardial fluid, concentrations of proteins, glucose, and lactate dehydrogenase activity are determined. What is more, microscopic and cytological evaluation and bacterial cultures should be performed [20]. Bloody fluid can be suggestive of a neoplastic process [11]. A diagnostic standard is cytological evaluation of the pericardial fluid; unfortunately, diagnosis cannot be established in about $30-50 \%$ of patients.

A neoplastic pericardial exudate should be considered in differential diagnosis of cardiogenic tamponade causes. Diagnostic management should include medical history, physical examination, echocardiography, ECG, chest X ray, chest $\mathrm{CT}$ and chest MRI.

Echocardiography enables a determination of the extent, morphology and location of a tumour. Herein, flow echocardiography is used to visualize the interatrial septum, 
pulmonary veins and superior vena cava, whereas, CT and MRI allow complete assessment of the location and extent of neoplastic lesions. CT better visualises calcifications within the tumour, while MRI is recommended for heart-infiltrating tumours.

Cardiac tumours should be suspected in cases of coexisting pulmonary embolism, cardiac failure, fainting and family history of cardiac neoplasms. Treatment involves pericardiocentesis, pericardiotomy, intrapericardial chemotherapeutics and radiation therapy. Despite the treatment, survival of patients after diagnosis is 7 days - 12 months, on average $[21,22]$.

In our case, dynamic progression of metastatic bronchial adenocarcinoma was observed. The first manifestation was cardiogenic shock induced by pericardial tamponade. On subsequent days of hospitalisation in the Department, bloody fluid additionally occurred in the pleural cavities; its volume consistently increased on follow-up thoracocentesis. Based on imaging examinations, long-term history of nicotinism and positive family history, a suspicion of lung neoplasm was put forward. The final answer was provided by the pathomorphology of biopsy samples collected during bronchoscopy. Bronchial adenocarcinoma was diagnosed, the most common histological type, in which pericardial tamponade is observed on the occurrence of metastatic symptoms. The time between the onset of symptoms and death was only slightly longer than 1 month.

Incidence of malignant cancers is increasingly high. Increased vigilance is, therefore, required in patients with non-specific symptoms, as the majority of cancers are only diagnosed in their advanced stages. Hence, the earlier the final diagnosis, the better the chances are of longer survival.

\section{REFERENCES}

1. Hanfling S.M.: Metastic cancer to the heart. Review of the literature and report of 127 cases. Circulation, 22, 474-483, 1960.

2. Fraser R.S., Viloriaa J.B., Wang N.: Cardiac tamponade as a presentation of extracardiac malignancy. Cancer, 45, 1697-1704, 1980

3. Griffith G.C.: A review of primary tumors of the heart. Prog. Cardiovasc. Dis., 7, 465, 1972.

4. Gilbert I., Henning R.J.: Adenocarcinoma of the lung presenting with pericardial tamponade: report of a case and review of the literature. Heart and Lung, 14, 83-87, 1985.
5. Pinto M.M.: Malignant pericardial effusion and cardiac tamponade. Acta Cytol., 30, 657-661, 1986.

6. Campione A. et al.: Which treatment in pericardial effusion? J. Cardiovasc. Surg., 43, 735-739, 2002.

7. Gilhert I., Henning R.J.: Adenocarcinoma of the lung presenting with pericardial tamponade: Report of a case and review of the literature. Heart Lung, 14, 83-87, 1985.

8. Muir K.W., Rodger J.C.: Cardiac tamponade as the initial presentation of malignancy: is it as rare as previously supposed? Postgrad. Med. J., 70, 703-707, 1994.

9. Haskell R.J., French W.J.: Cardiac tamponade as the initial presentation of malignancy. Chest, 88, 70-73, 1985.

10. Balghith M., Taylor D.A., Jugdutt B.I.: Cardiac tamponade as the first clinical manifestation of metastatic adenocarcinoma of the lung. Can. J. Cardiol., 16, 925-927, 2000.

11. Sobański P., Anna Adamczyk A.: Tamponada serca. Opis przypadku. Pol. Med. Paliat., 2, 1, 57-60, 2003.

12. Siniorakis E. et al.: Searching for pulsus paradoxus and correlates in cardiac tamponade. Int. J. Cardiol., 145, 127-1288, 2010.

13. Theologides A.: Neoplastic cardiac tamponade. Seniin Oncol, 5, 181-192, 1982.

14. Trusz-Gluza M. (1998). Stany zagrożenia życia pochodzenia sercowego. In: Ostre stany zagrożenia życia. Kokot F. (editor). Warszawa: PZWL.

15. Cheitlin M.D., Armstrong W.F., Aurigemma G.P.: ACC/AHA/ASE 2003 guideline update for the clinical application of echocardiography: summary article: a report of the American College of Cardiology/American Heart Association Task Force on Practice Guidelines for the Clinical Application of Echocardiography. Circulation, 108-1146, 2003.

16. O'Connor C.J., Tuman K.J.: Postępowanie śródoperacyjne u chorych z tamponadą serca. Anesthesiology Clin., 28, 87-96, 2010.

17. Pasierski T., Pikto-Pietkiewicz W. (2004). Choroby osierdzia. In: Echokardiografia Hoffman P., Kasprzak J.D. (editors). Gdańsk: Wydawnictwo Via Medica; p.288-291.

18. Bodson L., Bouferrache K., Vieillard-Baron A.: Cardiac tamponade. Curr. Opin. Crit. Care, 17, 416-24, 2011.

19. Tomkowski W., Kuca P.(2005). Choroby osierdzia. In: Choroby wewnętrzne. Szczeklik A. (editor). Kraków: Medycyna praktyczna.; p.297-306.

20. Troughton R.W., Asher C.R., Klein A.L.: Pericarditis. Lancet, 363, 717-727, 2004.

21. Campione A. et al.: Which treatment in pericardial effusion? J. Cardiovasc. Surg., 43, 735-739, 2002.

22. Wang P.C. et al.: Prognostic role of pericardial fluid cytology in cardiac tamponade associated with non-small cell lung cancer. Chest, 118, 744-749, 2000. 